\title{
THE NEW TOOL INSERT DESIGN FOR PREVENTION THE ROTATION OF HORIZONTAL WIRE DURING SHEAR TESTING OF WELDED FABRIC
}

\author{
Ivana Atanasovska ${ }^{*}$, Dejan Momčilović ${ }^{2}$, Ognjen Ristić ${ }^{2}$ \\ ${ }^{1}$ Mathematical Institute of the Serbian Academy of Sciences and Arts, Belgrade, Serbia \\ ${ }^{2}$ Institute for Testing of Materials, Belgrade, Serbia
}

Received 10.05.2019

Accepted 13.06.2019

\begin{abstract}
Many new requirements in the field of experimental mechanics, like testing of metallic materials, emphasize traceability and accuracy of test results as the end goal. These requirements have energy efficiency context too, due to the increase of mass productions of many finished and semi-finished products based on steel metallurgy. Combined, both of the above-noted perspectives impose the need for improvements of some of the existing test methods. This paper describes one such improvement, the developing of the new insert tool for testing of shear strength of the welded fabric, for civil engineering. The developed tool allows repeated testing of welded joints sampled from the welded fabric of different dimensions without tool changes and is generally related with the procedure for the determination of shear strength properties of different sizes of wires used for welded fabric. The construction of the tool insert allows aiming high operation safety and higher accuracy of results, which is described in detail. The paper also presents experimental results and the Finite Element Analysis performed in order to verify the impact of insert tool application on the testing results. The obtained results and conclusion about the possible contributions of the developed insert tool for extensively testing of welded fabric for civil engineering are discussed.
\end{abstract}

Keywords: prestressing steel; welded fabric; shear strength; Finite Element Analysis.

\section{Introduction}

Many commonly known procedures in the field of applied experimental mechanics, particularly related to civil engineering, have details which are not reevaluated for many decades. However, new requirements in the field of experimental

*Corresponding author: Ivana Atanaskovska, iatanasovska@mi.sanu.ac.rs 
mechanics (for example testing of metallic materials) regarding traceability and accuracy of test results, after many decades, impose the need for improvements of some of the testing methods. Testing of steel for the reinforcement of concrete is commonly considered as topic solved long time ago. Keeping this in focus, the requirements from areas of experimental mechanics of metallic materials and construction engineering, it is important to recognize two parallel processes: application of new measurement technologies and application on the newer generation of metallic materials. In the case of testing of prestressing steels, particularly in the testing of shear strength of the welded fabric, the tools itself are described in standards SRPS EN 10080: 2008 SRPS EN ISO 15630-2:2011 and ASTM A185/A185M-07 [1-3]. The noted standards specified properties and testing procedure of standard dimensions of the welded fabric, with all relevant details. It is possible to find papers related to this topic, too, with presented detail analysis of experimental testing of welded fabric up to failure but without details regarding testing setup and used tools [4]. Detail analysis of all aspects of testing of welded fabric is presented in a master thesis [5], and particular analysis is focused on weldments - the joint points of longitudinal and horizontal wires. The welded fabric have the function as an element in civil engineering only if all of the weldments have shear strength higher compared with the minimal values defined in standards [1-3]. Thesis [5] also gave the detail kinematic analysis of welded joint during testing and analytically and experimentally shown that during testing of commonly used tools additional torque occurs on the horizontal wire, which is strain component that decreases the accuracy of results. However, the proposal for minimizing torque, presented in this thesis, was the addition of a hollow piece that is putting on the upper part of vertical wire. The problem with this solution for minimizing of horizontal wire torque is that hollow piece must be made for each diameter of the wire. The testing procedure was performed with this hollow element only, and the weight of hollow element was found insufficient, and it is concluded that additional force is necessary to apply on a hollow element in order to nullify unwanted torque.

The key problem in the testing of the welded joint on welded fabric is revealed by the problem of how to nullify unwanted torque during testing. The torque of horizontal wire induces tearing of weldment instead shearing of horizontal wire on welded joint with longitudinal wire, Fig 1a. The same is also possible when the strength of weldment is significantly higher compared to the strength of the longitudinal wire, so deformation of longitudinal wire occurs in some moment during testing, Fig $1 \mathrm{~b}$. The existing tool designed according to standards [1-3] can be found on the web sites of producers, specialized for welded fabric [4-7], but the present solution does not prevent tearing of horizontal wire. The presented problem is solved by a new insert tool as an addition to the present tools, combining knowledge from metallurgy, mechanical, and civil engineering.

\section{Theoretical consideration of strain state during shear testing of welded fabric}

The scheme of the testing conditions with standard tools design is shown in Fig. 1. Note that in this case, the force $F_{R}$ does not act in a vertical direction, but follows the line of normal force $f_{n}$. This rotation of the force $F_{R}$ also has an accompanying torque. This momentum has a consequence on tearing of horizontal wire due to the increased moment arm, L, caused by the rotation of force. 


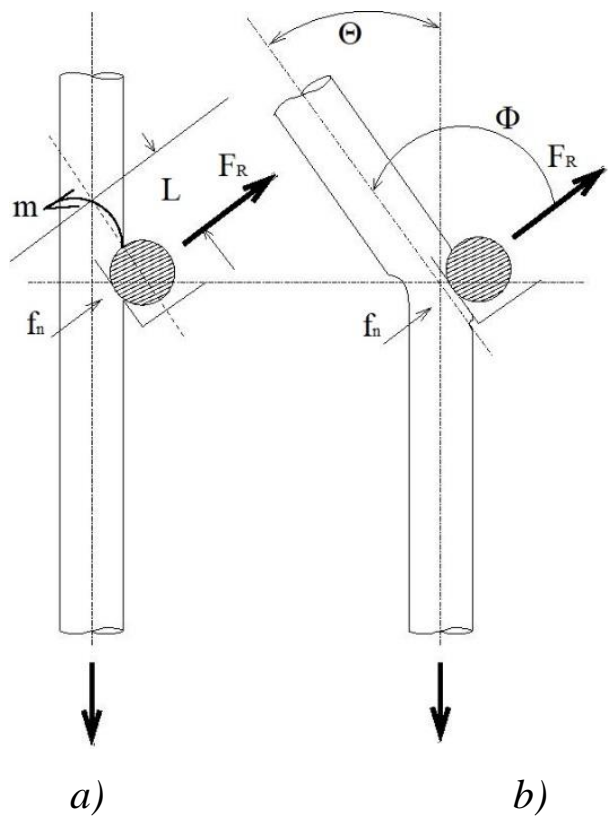

Fig.1. Scheme of strains during shear testing on standard tools without a new tool insert.

The moment induced by the eccentric forces as set up by the tool for testing and tend to rotate the upper arm of longitudinal wire. This rotation continues until the upperend contacts the face of the tester body. It has been noticed that the shorter the upper arm of the longitudinal wire, the more pronounced is the angle of rotation. This is a reasonable occurrence in that the shorter the upper arm, the more distance the arm can travel before contacting the supporting elements within the testing tool. This rotation, observed in every sample tested, has a very definite tearing on the type of break which occurs.

\section{Description of the new tool insert design}

The new tool insert design is made with the idea to block rotation from the beginning of testing, without any subsequent nullification, and it is filled for R.S. patent [7]. The design solution of the developed tool insert is shown in Fig. 2. The new tool insert, which is the subject of this paper has a complex shape (1), with ergonomically rounded holder at the end (5) which have the function of simple handling during repeated testing. The tool also has the serrated surface (4) which have a function to be in contact with the upper side of the horizontal wire, adjustable aperture (2) for linking with the base tool and orifice for the upper arm of the longitudinal wire during testing. The tool insert design is adapted to be universal for all standard sizes of welded fabric, Fig. 2b). The insert tool is linking with the body of the tool by bolt, while two other bolts hold supported rolls which have a function to halt bending during testing, shown of Fig. 1b). 


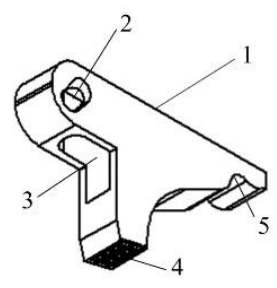

a)

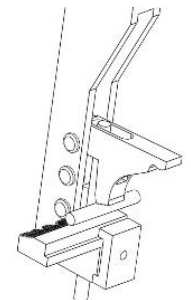

b)

Fig. 2. a) Axonometric view of new tool insert; $b$ ) Position of a new tool insert on standard tools for shear testing of weldments of welded fabric.

The new tool insert, shown in Fig. 2, is made from standard steel plate and have shape and dimensions chosen in such manner that fits into existing tools for testing of shear strength of welded joints on welded fabric. Aperture (2), from Fig. 2, is intended for linking with the body of the tool, and the shape of orifice allows self-adjusting to all standard diameters of wires used for the production of welded fabric. Orifice (3), from Fig. 2, have a cylindrical shape for the upper housing arm of longitudinal wire and allows smooth rotation during the exchange or setting new samples into a tool, Fig. 3. The serrated surface on tool insert which is during testing in contact with the upper surface of the horizontal wire, position (14) on Fig. 3, has slanted design in order to enable secure gripping of horizontal wire, and subsequently, disable any rotation of horizontal wire during testing.

Fig. 3 shows the positioning of the test specimen into a tool with a raised insert tool as an initial phase of testing. It is essential to remind that standard tool is inserting between upper and lower grips of the standard tensile testing machine, where lower grips clutching lower arm (the longer one) of longitudinal wire and by this produce tensile force, which act eccentrically on the horizontal wire, i.e. welded joint and induce shearing of the weldment.

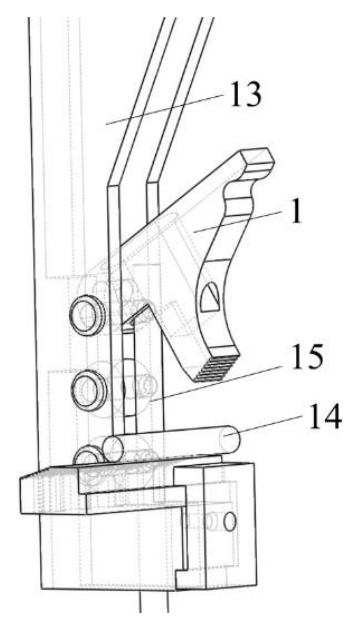

Fig. 3. Schematic view of the positioning of the test sample on the standard shear testing tool with new insert tool. 


\section{Verification of tool insert design - Experiment and FEA results}

The Finite Element Method [8, 9, 10] is select for verification of the new tool insert design. The full model of the standard testing tool with a mounted tool insert is developed in the finite element method. The calculations of stress and strain state of the elements are performed for the real strength force during testing depending on the wire diameter. On Fig. 4a) the developed finite element model for the testing tool with tool insert shown the VonMises equivalent stress state for the case of the wire diameter of $5 \mathrm{~mm}$. The material characteristics used for modeling the analyzed tool and tool insert are a Young module of $\mathrm{E}=205 \mathrm{GPa}$ and Poisson's ratio of 0,3 , and for wire finite element modeling: Young module of E=192GPa and Poisson's ratio of 0,3. The 3-dimensional solid finite element type with mid-side nodes is used for modeling the main parts of the developed universal tool. The obtained results fit with the expected results. The verification of the developed tool insert is given on the contour plots of vertical z-axis strains on Fig.4b) (zaxis is matched with the axis of the longitudinal wire of welded fabric). Z-axis strains shown in Fig.4b) for welded fabric sample verify that only the longitudinal wire is strained during the testing, while horizontal wire remains fixed by the tool insert application.

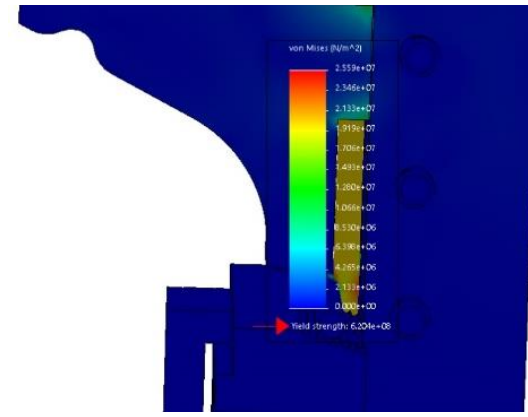

a)

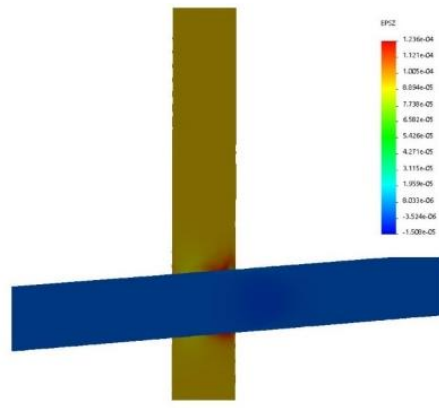

b)

Fig. 4. FEA results for: (a) equivalent VonMises stresses during testing (b) z-axis strain on welded fabric sample during testing.

The verification of the effect of the developed tool insert is also performed by experiment. The samples of the welded fabric with the same dimension are testing on the universal testing machine with and without tool insert. The obtained results are shown in Table 1 and comparative bars display on Fig. 5. In order to provide maximal traceability of results, the samples for testing were sampled from the same row, which means that the mechanical properties of longitudinal wires were the same in all presented cases. Due to the process of resistance welding, the only variations were the positions of horizontal wires. This helps in ensuring the very basic idea of enabling only shearing during testing instead tearing, which are very distinct not only by appearance but also by obtained results expressed by breaking (shearing) force [11]. 
Table 1. The verification results obtained by experiments.

\begin{tabular}{|c|c|c|c|c|}
\hline & $\begin{array}{c}\text { Nominal } \\
\text { diametar, } \\
5 \mathrm{~mm} \\
\text { (max diameter / } \\
\text { min diameter) }\end{array}$ & $\begin{array}{c}\text { Nominal } \\
\text { diametar, } \\
6 \mathrm{~mm} \\
\text { (max diameter / } \\
\text { min diameter) }\end{array}$ & $\begin{array}{c}\text { Nominal } \\
\text { diametar, } \\
7 \mathrm{~mm} \\
\text { (max diameter / } \\
\text { min diameter) }\end{array}$ & $\begin{array}{c}\text { Nominal } \\
\text { diametar, } \\
8 \mathrm{~mm} \\
\text { (max diameter / } \\
\text { min diameter) }\end{array}$ \\
\hline & $4.99 / 4.98 \mathrm{~mm}$ & $5.94 / 5.92 \mathrm{~mm}$ & $6.99 / 6.98 \mathrm{~mm}$ & $7.98 / 7.99 \mathrm{~mm}$ \\
\hline Tool insert & & Breakin & force $\mathrm{N}$ & \\
\hline with & 5.7 & 7.0 & 6.7 & 17.7 \\
\hline without & 5.9 & 7.7 & 7.1 & 18.6 \\
\hline with & 7.9 & 6.4 & 7.9 & 13.4 \\
\hline without & 7.8 & 6.1 & 8.2 & 14.1 \\
\hline with & 6.2 & 6.5 & 8.1 & 15.6 \\
\hline without & 7.0 & 6.9 & 8.3 & 15.7 \\
\hline with & 4.3 & 5.7 & 6.9 & 14.9 \\
\hline without & 4.9 & 6.1 & 7.8 & 16.9 \\
\hline with & 7.1 & 4.5 & 8.4 & 16.3 \\
\hline without & 7.6 & 5.1 & 8.3 & 16.1 \\
\hline with & 6.3 & 7.1 & 7.7 & 15.9 \\
\hline without & 6.5 & 7.8 & 8.0 & 16.2 \\
\hline with & 4.2 & 5.3 & 7.1 & 17.1 \\
\hline without & 4.4 & 5.5 & 8.7 & 18.2 \\
\hline with & 5.1 & 5.8 & 8.3 & 14.2 \\
\hline without & 5.3 & 5.9 & 9.5 & 15.0 \\
\hline with & 4.8 & 4.9 & 5.9 & 14.7 \\
\hline without & 4.7 & 4.7 & 6.1 & 15.1 \\
\hline with & 5.3 & 6.1 & 6.4 & 15.1 \\
\hline without & 5.2 & 6.4 & 6.7 & 15.7 \\
\hline
\end{tabular}




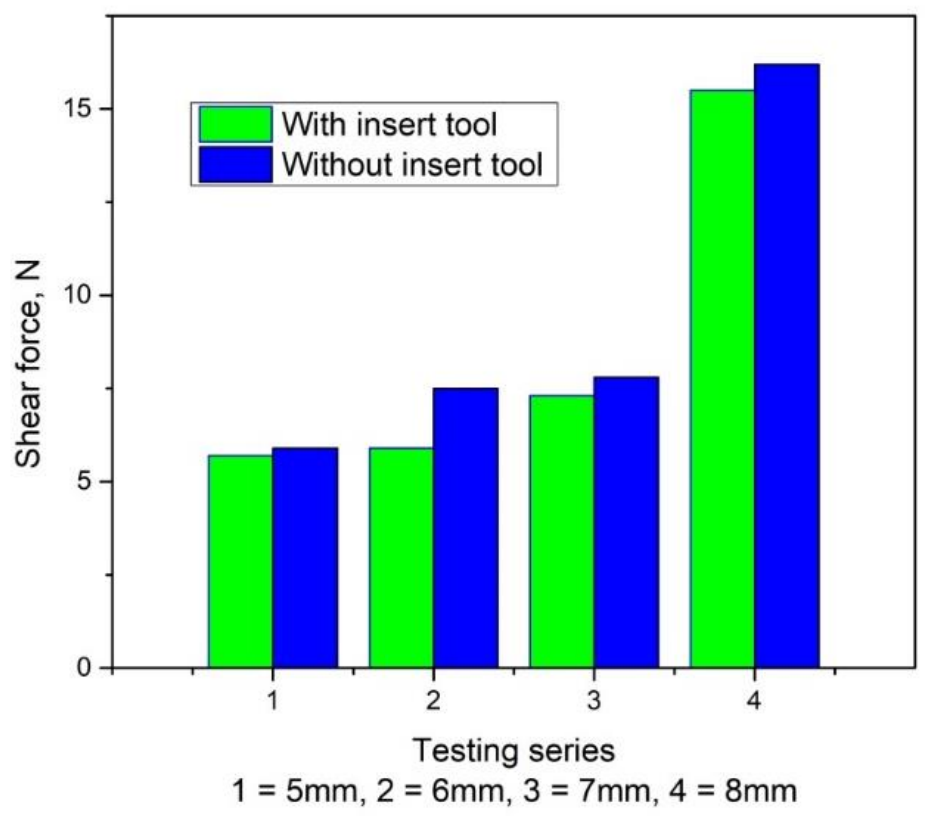

Fig. 5. Comparative experimental results.

\section{Conclusions}

This paper describes the design of insert tool for total prevention of rotation of horizontal wire during shear testing of weldments on welded steel fabric. The use of presented tool insert is possible to almost all existing tools for shear testing of weldments on welded fabric, regardless of the diameter of used wire for the production of welded fabric. The basic idea was to obtain more accurate and traceable results without interfering with very basic simplicity of handling and operating with tool and test procedure. The new insert tool design has also the following advantages:

- low production price, due to simplicity;

- handling simplicity, without affecting the time necessary for testing one sample;

- increase confidence in obtaining results, due to reducing scatter of data; and

- increase of safety during operation.

The new insert tool design also has one additional feature. Due to the halting rotation of horizontal wire, the mechanism of failure of welded join is shifted from tearing toward shearing, which explains lower obtained result on tested specimens. This means that application on the new insert tool gives more conservative results compared with results without insert tool, which is essential from the safety point of view. Increased demands of new constructions match well with the potential application of a new tool insert. 


\section{References}

[1] ASTM A185/A185M-07: 2007: Standard Specification for Steel Welded Wire Reinforcement, Plain, for Concrete

[2] EN 10080: 2008: Steel for the reinforcement of concrete

[3] SRPS EN ISO 15630-2:2011 - Steel for the reinforcement and prestressing of concrete - Test methods - Part 2: Welded fabric (ISO 15630-2:2010)

[4] E Villaescusa: Rock Support and Reinforcement Practice in Mining (1999) 155159 , https://www.researchgate.net/publication/269932060, Accessed 10 May 2019.

[5] E. C. Kobs, A comparative determination of weld shearing values in welded wire reinforcement fabric, M. Sci. Theses, Missouri University of Science and Technology, 1957.

https://scholarsmine.mst.edu/masters_theses/4161/ Accessed 10 May 2019.

[6] Wyoming Test Fixtures Inc., Weld shear test fixture, http://www.wyomingtest fixtures.com/Products/i6.html, Accessed 08.11.2018.

[7] Sophia High Tech, ASTM A497 \$ A185 Testing Fixture, http://www.sophiahightech.com/en/astm-497-185-testing-fixture, Accessed 08.11.2018.

[8] I. Atanasovska et al., The tool insert for prevention the rotation of horizontal wire during shear testing of welded steel mesh, R.S. Patent Application number MP2019/0021, filed March 29, 2019.

[9] E. Ranjbarnodeh, Anzabi Y.G. and H. Sabet: Metall Mater Eng, 22 (2016) $237-$ 250.

[10] M. M. Reddy, Kumar B. M., Kumaraesan S.: Metall Mater Eng, 24 (2018) 59-69.

[11] I. Atanasovska, Momcilovic D., Gavrilovski M.: Metall Mater Eng, 24 (2018) 113-122.

[12] González-Velázquez, Jorge Luis, Fractography and Failure Analysis, Springer International Publishing, 2018, 24.

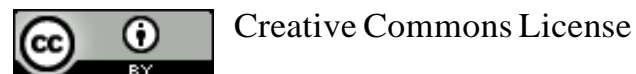

This work is licensed under a Creative Commons Attribution 4.0 International License. 